\title{
The Effect of Teacher Beliefs on Student Competence in Mathematical Modeling - An Intervention Study
}

\author{
Christoph Mischo ${ }^{1} \&$ Katja Maaß ${ }^{2}$ \\ ${ }^{1}$ Department of Psychology, University of Education Freiburg, Germany \\ ${ }^{2}$ Institute of Mathematics Education, University of Education Freiburg, Germany \\ Correspondence: Christoph Mischo, Department of Psychology, University of Education, Kunzenweg 21, 79117 \\ Freiburg, Germany. E-mail: mischo@ph-freiburg.de
}

Received: December 14, 2012 Accepted: December 28, 2012 Available online: January 6, 2013

doi:10.11114/jets.v1i1.24

URL: http://dx.doi.org/10.11114/jets.v1i1.24

\begin{abstract}
This paper presents an intervention study whose aim was to promote teacher beliefs about mathematics and learning mathematics and student competences in mathematical modeling. In the intervention, teachers received written curriculum materials about mathematical modeling. The concept underlying the materials was based on constructivist ideas and findings from mathematics education. Teacher beliefs about mathematics, learning and self-efficacy were expected to have a major impact on their classroom practices. We therefore assessed teacher beliefs about the usefulness of mathematics, learning (constructivist and socio-constructivist beliefs) and teacher self-efficacy when teaching modeling (teacher or class level variable). The student level variables assessed were modeling competence and other individual factors, such as basic mathematical skills and cognitive abilities.

The effectiveness of the intervention was measured in a pre-post control group design using multilevel structural equation modeling. The results showed no direct effect of the intervention on student modeling competence. However, they did reveal that the intervention had a significant effect on teacher beliefs about learning (constructivist and socio-constructivist view) and an effect of these teacher beliefs about learning on student modeling competence. Further, the results showed that students' gains in modeling competence is not only mediated by teacher beliefs, but also influenced by individual factors. Implications for teaching as well as limitations of the study are discussed.
\end{abstract}

Keywords: teacher beliefs, teacher education, mathematical modeling, teacher training

\section{Theoretical Background}

\subsection{Introduction}

Mathematical modeling means solving complex, realistic and open problems with the help of mathematics. Although mathematical modeling became part of the national German curriculum in 2004 and has been discussed among mathematics educators for decades, it is still rare in day-to-day teaching practice (Blum, 2002).

In the present study, we wanted to know whether specially designed (written) curriculum materials for teachers support the development of students' modeling competences. We focused on the design of curriculum materials because materials - other than long-term teacher training - can reach many teachers easily and effectively. We designed mathematical modeling teaching materials for the target group of six grade students (age 11) because modeling is part of the curriculum for this grade. Teachers were asked to use these materials over a period of one school year. The effectiveness of the materials was evaluated in a pre-post control group design by means of a standardized test to assess student competences in mathematical modeling. We also assessed teacher beliefs before and after the intervention because it was expected that their beliefs play a mediating role in the effectiveness of the written materials.

The main research questions of the study were:

1. Does teacher use of curriculum materials directly influence student modeling competences?

2. Do these materials affect teacher beliefs?

3. Do teacher beliefs mediate a potential effect of the teaching materials on student modeling competence?

4. Which student characteristics influence acquisition of modeling competence? 
The study presented in this article is a research and design project that aims to bridge the theory-practice gap by designing teaching units for everyday teaching practice and not within an ideal laboratory situation. The research design had to take this factor into account.

The theoretical background outlined below will give the rationale for our approach. We will provide an introduction to the field of mathematical modeling and outline relevant student characteristics for mathematical modeling before we discuss the role of teacher beliefs and curriculum materials.

\subsection{Mathematical Modeling}

\subsubsection{Definition of Mathematical Modeling}

Within the discussion of mathematics education, there are various definitions of mathematical modeling (Kaiser \& Sriraman, 2006). What modeling means in detail is mostly described by listing the steps of a so-called modeling process. We will clarify the modeling process by means of an example modeling task.

The task starts with an excerpt from a German newspaper:

"It is a well-known fact that if you let the water run while brushing your teeth, a family of four will waste 26,000 liters of water per year." The newspaper article says that every family can save 26,000 liters of water every year if they turn off the faucet when brushing their teeth. What do you think about this? Is it really possible? Give reasons!"

In solving this modeling task, students first have to understand the instructions and the real situation (Step 1, understanding the real situation).That means they have to construct a mental model of the situation (situation model). In the next step, they have to simplify the situation (e.g. we estimate that an "average" family is of a certain size and will assume that every day, family members spend a certain amount of time brushing their teeth (Step 2, construction of a real model). Next, the real model must be transformed into a mathematical model by the use of estimates (e.g. assuming that: a person brushes their teeth twice a day for three minutes; a family has an average of four members; and that in ten seconds, about 0.5 liters of water are used. The latter because it might be easier to estimate the amount of water running through a faucet in ten seconds rather than to estimate for one second or 60 seconds). Hence students may construct the formula: 3 minutes $=18 \times 10$ seconds (three minutes teeth brushing is $18 \times 10$-secondintervals); 18 x 0.5 liters $\times 4$ people $\mathrm{x} 2$ times a day x 365 days (Step 3 , mathematizing). By doing so, students transform the real model into the numbers and arithmetic operations. Doing the actual calculations is the next step: $18 \times 0.5=9$ and $4 \times 2 \times 9=72$ and $365 \times 72=26,280 \approx 26,000$ (Step 4, working within the mathematical model). The mathematical solution has to be interpreted in terms of the "reality" presented in the modeling task (26,000 means that 26,000 liters of water are used or "wasted.”(Step 5, interpreting). Finally, students have to appraise whether the interpreted solution is plausible, for example with questions such as: "Is 26,000 liters realistic?”; "Did I proceed in a correct way?” and "Are the estimates reasonable?”(Step 6, validating, see Blum \& Leiss, 2005, p. 19.)

There are many illustrations of the mathematical modeling process (see e.g. Burkhardt, 2006, p. 181; Verschaffel et al., 1999, p. 202). We have chosen the following to use as our basis (see Figure 1).

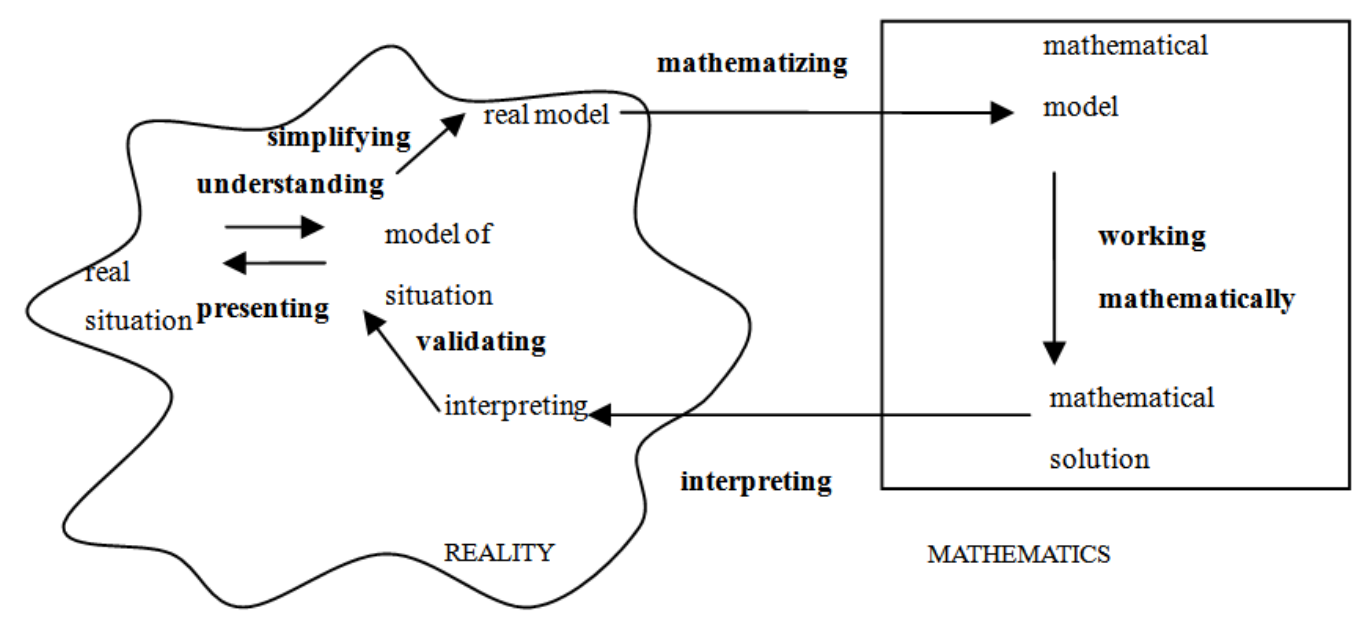

Figure 1. Diagram about mathematical modeling used in the curriculum materials for teachers

This scheme of the modeling process forms the basis for the assessment of modeling competence and for the 
design of the teaching units in the presented study. Of course, these steps are to be seen as an idealized scheme. This does not mean that every step postulated in the scheme corresponds to the actual cognitive processes of every individual or the way in which they choose to solve the problem. As has been shown, students' actual "modeling routes" (ways through the modeling process) can look very different (Borromeo-Ferri, 2007). Further, as the example above shows, sometimes (in particular with simple tasks) some distinctions between the single steps -as in calculation and interpretation above - seem to be a bit artificial. Nevertheless, the scheme is meaningful because it gives an impression of what aspects have to be taken into account.

\subsubsection{Modeling Competence and Individual Factors Affecting It}

There is not general consensus in regards to describing the concept of "modeling competences"(see Blum \& Alsina, 2002).While several researcher agree that modeling competences include certain sub-competences in carrying out the above mentioned steps of the modeling process, such as setting up a real model or mathematizing such a model, it is often said that those sub-competences relating to the process of modeling are not sufficient to characterize modeling competences (e.g. Maaß, 2006).

In educational research, different factors that affect learning outcomes have been identified (Wang, Haertel, \& Walberg, 1993; Helmke \& Schrader, 2001). The main ones can be divided into three categories. Firstly, there are the personal factors which are individual determinants, such as cognitive abilities (intelligence, knowledge), motivational determinants, and domain specific and cross-domain competences. The second factors are the determinants of classroom quality and quantity (e.g. time on task, instructional clarity). Finally, the determinants of a student's family environment (such as parental help or parental stimulation) also affect learning outcomes (Helmke \& Schrader, 2006, p. 84).

From all the factors listed above, prior knowledge, prior competences and intelligence are the most relevant. (Wang, Haertel \& Walberg, 1993; Helmke \& Schrader, 2001, 2006). For this reason we considered the following personal factors as covariates:

\section{- Students' prior competences in modeling;}

- Basic mathematical skills, like the mathematical, factual knowledge and technical skills (in accordance with the curriculum) which might be necessary when setting up the mathematical model and working within it. However, basic mathematical skills are not sufficient when one considers the entire process involved in mathematical modeling (for details see Mischo \& Maaß, in press).

- Fluid intelligence. Following Cattells terminology (Cattell, 1971), fluid intelligence refers to nonverbal, logical reasoning ability which is the best indicator for general intelligence and a powerful predictor for any cognitive performance.

- Crystallized intelligence is most often assessed by general knowledge or word comprehension tasks and is the product of educational and cultural experience in interaction with fluid intelligence (Cattell, 1971).

\subsubsection{Teaching Mathematical Modeling}

In the definition of modeling used here, modeling tasks differ significantly from traditional, mathematical word problems, as these often have artificial contexts, exactly one correct solution and often ignore student everyday life experiences (Verschaffel, 2002). These differences between mathematical word problems and modeling tasks may illustrate that the use of modeling tasks might be regarded as a challenge for students - and teachers as well.

The challenge becomes even more evident when looking at the teaching of modeling. Although one could imagine teaching modeling in a more teacher-centered way, the explanation of modeling suggests more open ways of teaching. Qualitative studies suggest that group discussions and students working both autonomously and in small groups support the development of mathematical modeling competences better than other forms of working (Galbraith \& Clatworthy 1990, p. 158). This difference between traditional teacher-centered ways of teaching and the teaching modeling hypothesis that teacher beliefs about teaching and learning, may play a major role when trying to teach modeling.

\subsection{Teacher Beliefs}

\subsubsection{Teacher Beliefs about Mathematics}

There are many different definitions of beliefs in the field of mathematics education (Eynde, De Corte, \& Verschaffel, 2002; Pehkonen \& Törner, 1996). Following Pekohnen and Törner (1996) we define beliefs as being composed of long-lasting, subjective knowledge of certain objects, as well as the attitudes linked to that knowledge. This definition refers to the fact that beliefs are considered to be hard to change (Törner, 2002). In 
regards to the convertibility of beliefs, it is assumed that peripheral beliefs - beliefs of lower importance to a person - are easier to change than central beliefs (beliefs of high importance, see Furenghetti \& Pehkonen, 2002). Some studies indicate that beliefs can be changed under certain circumstances (Kaasila, Hannula, Laine, \& Pehkonen, 2006; Maaß, 2004).

Beliefs in the context of mathematics education refer to beliefs about mathematics (as a science), beliefs about the learning and teaching of mathematics (see e.g. Cai, Kaiser, Perry, \& Wong, 2009; Grigutsch, Raatz, \& Törner, 1998; Törner, 2002) and teacher self-efficacy beliefs.

Regarding beliefs about mathematics, Grigutsch and colleagues differentiate between the following aspects (Grigutsch et al., 1998): scheme (mathematics is a fixed set of rules); process (in mathematics, problem-solving processes are carried out); formalism (mathematics is a logical and deductive science); and utility and application (mathematics is useful for life and society). Similar categories can be found in other studies (e. g. Dionne, 1984). The utility aspect of beliefs seems to be particularly relevant for mathematical modeling, as the aim of mathematical modeling is to solve authentic everyday problem by means of mathematics.

\subsubsection{Teacher Beliefs about Learning and Teaching}

Regarding beliefs about the learning and teaching of mathematics, Staub and Stern (2002) distinguish between a transmission view (learning as the result of information transmission and repetition by the learner) and a constructivist or socio-constructivist view. According to the latter, learning depends on the individual's active cognitive processes; moreover, a socio-constructivist view emphasizes the role of social exchange (e.g. between students) for individual, active cognitive processes (Prawat, 1992). As Staub and Stern (2002) illustrate, a (socio-) constructivist orientation of the teachers is associated with students achieving higher scores in solving mathematical word problems. Other findings support the relevance of teacher constructivist beliefs regarding student learning outcomes in mathematics (Dubberke, Kunter, McElvany, Brunner, \& Baumert, 2008; Stipek, Givvin, Salmon, \& MachGyvers, 2001).

Considering the concept of mathematical modeling stated above, a constructivist and socio-constructivist view of teaching seems to "fit" to the teaching of modeling, as mathematical modeling requires that students develop their own approach to solving modeling tasks.

\subsubsection{Teacher Self-efficacy Beliefs}

In addition to beliefs about mathematics and teaching mathematics, teacher efficacy beliefs were of major importance for our study (Bandura, 1997). Self-efficacy denotes the degree to which an individual believes that they are able to show behavior that leads to a goal pursued by the individual. Teacher efficacy beliefs refer to a teacher's conviction that they are able to act in such a way that will result in achieving their goals. Teachers with high self-efficacy are also more likely to implement didactic innovations, to show effective classroom management and to foster the learning motivation of students with special learning needs (Caprara, Barbaranelli, Steca, \& Malone, 2006; Ross, 1998). As implementing modeling tasks in lessons makes great demands on teachers, we focused on the teacher self-efficacy beliefs about being able to foster student modeling competences. The question arises of whether the modeling specific self-efficacy beliefs teachers hold can be improved by teaching materials and lead to better student performance in mathematical modeling.

\subsubsection{Role of Teacher Beliefs for Behavior and Behavior Change}

Teacher beliefs can - and do influence their actions, and thus can be enacted beliefs (Pajares, 1992; Schoenfeld, 1992; Stipek, Givvin, Salmon, \& MacGyvers, 2001). In contrast to these researchers, Ruthven (1987) as well as Cobb, Wood and Yackel (1990), argue that beliefs are more the results of actual practice, rather than preceding practice. Other research supports the view that changes in teacher beliefs and practices are an interactive process, with each influencing the other (Richardson \& Placier, 2001).

The role of teacher beliefs on the effectiveness of teacher training was studied by Tillema (1995). In his study, teacher beliefs existing before professional training filtered the knowledge acquisition process in the training. The greater the correspondence between a teacher's preexisting beliefs and the content of the training, the higher the amount of learning they gained from the training was. Hence, Tillema concluded that the acquisition process in teacher training depends on the preceding or accompanying change of beliefs.

Maaß (2011) reconstructed teacher beliefs about teaching and learning in the framework of a professional development course on modeling and identified the static type and the process type. The static type aims to prepare students efficiently for their final exam, while the process type expects students to learn to apply mathematics in real life. They also perceive the context in different ways: Whilst the first type considers the context as an impediment, the second considers it as a challenge to be overcome. Hence, holders of the latter 
type of belief try to implement mathematical modeling, while holders of the former type try to avoid doing it.

Therefore, in order to implement new tasks or to change teacher classroom practices, teacher beliefs should be taken into account.

\subsection{Role of Teaching Materials for Teaching Behavior and Behavior Change}

There is a vast amount of available teaching materials that either support current teaching practice or encourage changes in the way teachers teach(Gunnarsdottir \& Palsdottir, 2010; McDuffie \& Mather, 2006). A growing body of research shows that teaching and curriculum materials affect the instructional practice and student learning (Ross, McDougall \& Hogaboam-Gray, 2003; Schoen, Cegulla, Finn, \& Fi, 2003; Stein, Smith, Henningsen, \& Silver, 2000). However, this research also found that teaching and learning is determined not only by the actual instructional materials (e. g. the tasks' reference to reality), but also by other factors such as the curriculum, teacher beliefs, teachers' personal backgrounds and professional experiences and their interactions with students The qualitative analyses of McDuffie and Marther (2006) give an insight into the interplay of a teacher's use of curriculum materials, their beliefs about mathematics and learning, and the "enacted curriculum": Teacher beliefs influenced the selection and implementation of problem based mathematical tasks.

Summing up, teaching materials and teacher beliefs can be considered as a relevant variable affecting teaching and learning outcomes. Although there have been many studies about teacher beliefs and their effects on teaching and learning, some questions remain open. Currently, it is not clear in how far curriculum materials directly affect student learning gains, or in how far materials have an influence on teacher beliefs and, as a consequence, the influence this has on student competences (indirect effect). In particular, there is no study which connects teaching materials about mathematical modeling with teacher beliefs and learning outcomes. Further, there seems to be a demand for more quantitative research to account for teacher beliefs and learning outcomes simultaneously in testing the effectiveness of curriculum materials (Heck, 2009). Accordingly, this quantitative study focused on student performance in modeling as a consequence of teachers using specially designed curriculum materials and simultaneously, evaluated teacher beliefs.

\section{Hypotheses}

\section{Hypothesis 1}

Students in classes where teachers received teaching materials show higher modeling competence after the intervention than students in classes without teaching materials (control group).

\section{Hypothesis 2}

After the intervention, teachers who received the materials will show a higher degree of promoting beliefs about mathematics (usefulness of mathematics), beliefs about learning (constructivist and socio-constructivist view), and to a higher degree self-efficacy about fostering student modeling competence in the posttest than teachers from the control group.

\section{Hypothesis 3}

The greater the degree of promoting beliefs about mathematics, learning beliefs and self-efficacy beliefs teachers have, the better student performance in mathematical modeling will be. Thus, the intervention effect on student mathematical modeling competence is mediated by teacher beliefs.

\section{Hypothesis 4}

Student acquisition of modeling competences is not only influenced by the materials and/or the teacher beliefs, but also by their basic mathematical skills, fluid intelligence and crystallized intelligence.

\section{Method}

\subsection{Design of Materials and Teacher Training}

For the development of our materials, we focused on eleven year old students at the German Hauptschule (see footnote) which is generally presumed to represent the lowest performance level ${ }^{1}$. We assume that our materials can be used for low-achieving students in general.

\footnotetext{
${ }^{1}$ In Germany, there are mainly three types of secondary schools (Gymnasium, Realschule, Hauptschule), which are designed to separate students according to their performance level. However, the results of PISA (Klieme, Neubrand, \& Lüdtke, 2001, p. 180) revealed that there is a considerable degree of overlap in student performance levels at the three types of schools. At the Hauptschule, about 45 percent of the students come from families with a low social-economic status, and the percentage of students with a migration background is high (Baumert \& Schümer, 2001, p. 355).
} 
Written materials that included teaching units had to be designed for the intervention. Altogether, 13 teaching units were developed. Between the modeling lessons, teachers were told to teach as the pleased and work with the materials they normally used. Each of our 13 teaching units comprised one or two lessons. Teachers were supposed to implement the materials every two weeks between November 2008 and May 2009. Teachers were not only given the teaching units (including lesson plans and worksheets), but also guidelines. These guidelines included an introduction with general explanations for modeling based on our theoretical concept of it as outlined above and, information about the constructivist/socio-constructivist teaching approach, and explanations for each individual teaching unit in accordance with this approach.

Based on Taylor, Fraser and Fisher (1997) and Aldridge, Fraser, Taylor and Chen (2000), we accounted for the following (socio-)constructivist characteristics in our materials and teacher training: uncertainty (e.g. different solutions for modeling tasks possible); student negotiation (e.g. teachers were encouraged to implement group discussions); shared control (e.g. by cooperative learning); critical voice (e.g. by encouraging teachers to allow critical discussions); and personal relevance (everyday relevance of modeling tasks). In order to facilitate the implementation of these characteristics in the lessons, explanations were given about such issues as: how to give only minimal help; how to encourage discussion among students; how to deal with students' mistakes in a constructive way; how to support students in working independently, and how to assess students work.

The teaching units comprised modeling tasks which were adjusted to student performance levels and covered realistic thematic contents from everyday life. We followed a structured approach to the introduction of mathematical modeling which (a) accounted for the fact that students and teachers are novices in mathematical modeling, and (b) was appropriate for the student performance level. Thus, in our teaching units, successive competences in carrying out the single steps are developed following the modeling process as described above (for details of the lessons and teaching units see Maßß \& Mischo, 2011).

\subsection{Evaluation Design}

In order to evaluate the effectiveness of the newly developed teaching units, a pre-post-control group design was applied. We designed questionnaires to assess teacher beliefs, teacher knowledge and student performance in modeling before and after the intervention. Pretest questionnaires were completed in October 2008, posttest questionnaires in June 2009. However, due to constraints on research resources, we could not observe teacher classroom practices.

\section{Assignment to intervention groups vs. control group}

Teacher participation in the study was voluntary. For this reason, the selection of teachers based on their willingness to participate in the study might be considered to be a pre-selection influence on the results of the study. However, this is a typical limitation of quasi-experimental designs (Shadish, Cook, \& Campbell, 2002). Some of the participating teachers had already encountered or even used mathematical modeling and therefore might differ in their beliefs before training. However, one of our interests was to test the effectiveness of the materials especially for teachers without prior knowledge and experience in mathematical modeling. Hence, we designed two intervention groups:

1. "Materials only": Teachers only received materials and had no further training

2. "Materials and training”: Teachers received materials and a one-day teacher training session.

Teachers without prior knowledge were assigned randomly to the intervention group "materials and training” or to the group "materials only." Those teachers, however, with prior experience were assigned to the intervention group "materials and training." One aim of the intervention group "materials and training" was to bring all teachers in this group up to the same level of knowledge about mathematical modeling. As implementing curriculum materials may be enhanced by a supportive teacher training (Angantysdottir, 2010), a second aim was to find out whether a one-day-training session is helpful for teachers in adopting the curriculum materials and thereby has an incremental effect on the effectiveness of the curriculum materials (i.e. student modeling competences). In this one-day training session, we basically dealt with the guidelines and the use of the materials. This session comprised the following topics: What is modeling? Why modeling? How to teach modeling with low achieving students? How to give feedback? Which steps of modeling can be fostered by which teaching units? How to deal with the materials?

Teachers in the control group received the materials after the intervention. Therefore the control group was in fact a "group in waiting." Nevertheless, as outlined above the design did not comprise a completely random assignment. Teacher beliefs and the measured student variables were controlled statistically. Hence, a quasiexperimental design with pretest and posttest was applied (see table 1). 
Table 1. Design of the study

\begin{tabular}{lclc}
\hline Group & Pre-test & \multicolumn{1}{c}{ Intervention } & Posttest \\
\hline Material & $\mathrm{O}$ & Written teaching units & $\mathrm{O}$ \\
Material plus training & $\mathrm{O}$ & Written teaching units plus one-day training & $\mathrm{O}$ \\
Control & $\mathrm{O}$ & Normal lessons & $\mathrm{O}$ \\
\hline
\end{tabular}

Note. $\mathrm{O}=$ Observation - measurement of mathematical modeling (students) and beliefs (teachers).

\subsection{Participants}

Altogether 54 teachers and their classes (grade six) were recruited from the local area of Freiburg in Germany. Of the total sample of 54 teachers, only 48 teachers completed pre and posttest questionnaires without any missing values. For one posttest teacher variable, there were six missing values, for four posttest variables, there were four missing values. None of the missing values were in the smallest group, and the pattern of missing data was completely random (Little, 1988). Missing teacher data at class level (teacher beliefs) and missing student data at individual level were estimated separately using an imputation approach (Schafer, 1997; maximum likely estimation with the software NORM, Schafer, 2000). The total sample, including imputed data, consisted of 54 classes and 959 records (students).

In order to overcome possible differences between the intervention groups, teacher beliefs and student measures (both at pretest) were taken into account as covariables. Altogether, 17 classes received no materials (332 students, control group), 24 classes received written materials only (407 students) and 13 classes received written materials plus a one-day teacher training session (220 students). From the total sample, 58.5 percent were boys $(\mathrm{n}=560), 41.5$ percent were girls $(\mathrm{n}=398)$, one missing data. Forty-six percent of the teachers were male $(\mathrm{n}=$ 25), 54 percent female $(n=29)$. The teacher mean age was 45.35 (standard deviation -SD $=10.40$ ). In order to control for pretest teacher differences, the following variables were also assessed: number of completed enhanced teacher training sessions, motivation to complete questionnaires and motivation to take part in the study.

\subsection{Information about the Implementation of the Teaching Units}

At the end of the study, teachers in the treatment groups completed a questionnaire about the implementation ("How many of the proposed lessons did you realize?"). Twenty percent of the teachers implemented eight to ten lessons while 80 percent implemented 11 to 13 lessons. Furthermore, we asked teachers whether they had been able to implement lessons as proposed in the materials (from $1=$ "not as proposed" to 4 = "as proposed"). Only two teachers (6.4 percent) answered that they had not been able to implement lessons as proposed at all, three teachers (9.7 percent) answered they had hardly been able to implement lessons as proposed, 11 (35.5 percent) answered they had been able to implement lessons almost as proposed and 15 (48.4 percent) stated that they had implemented lessons as proposed (mean value: 3.26 on a four point scale; two teachers had missing values on this variable, $\mathrm{SD}=.89$ ). Hence, about 84 percent of teachers in the treatment groups reported that the lessons had been implemented as proposed or almost as proposed. Teachers rated the usefulness of written materials as high (mean value 3.33 on a four point rating scale from $1=$ "not useful" to 4 = "very useful"). Based on this data, it can be assumed that materials and lessons were implemented almost as proposed and planned, at least from the teacher perspective.

\subsection{Assessment of Dependent Variables and Covariates}

\subsubsection{Teacher Level}

Teacher beliefs about the usefulness of mathematics were assessed using the mean score of five items adapted from Grigutsch, Raatz, and Törner (1998, p. 22; example item "Mathematics helps students to solve real world problems"). Beliefs about learning were assessed applying two scales of Staub and Stern (2002): the scale "role of learner as active" (6 items, example item: "Students learn best when they explore solutions by themselves") and scale "socio-constructivism" (6 items; example item: "Teachers should help students to find their own solutions"). Self-efficacy in teaching modeling was measured by means of five items adapted from Schmitz and Schwarzer (2000; example item: "I feel confident about fostering student modeling competence").All items had a four point rating scale answering format ( $1=$ "agree" to $4=$ "do not agree"). The covariables age, gender, number of completed enhanced teacher trainings, motivation to complete questionnaires and motivation to take 
part in the study were assessed in questionnaires (multiple choice-ratings and self-ratings on a four point rating scale). Other teacher variables were also assessed, but are not relevant in the context of the present study.

\subsubsection{Student Level}

\section{Modeling competence}

A modeling test was constructed which assessed modeling competence in a multiple-choice format as suggested and empirically evaluated by Haines, Crouch and Davies (2001).

The multiple choice format contained six items for each of the six steps of the modeling process, and for each multiple choice item, five answer options were presented. From these answer options; several had to be ticked as "right" (for more details see Maaß \& Mischo, 2011). The modeling task that follows is one of the more simple ones used, as only one variable has to be estimated (number of people per apartment). For this task, we demonstrate in example questions b, c, and d three of the six modeling process steps. These are: step 2, simplifying the situation (question b below); step 3, mathematizing (question c below); and step 4, working within the mathematical model (question d).

\section{Example task "Tower Block"}

Linda lives in a tower block. She wants to work out how many people live in the same building as she does. The block has 8 floors. On every floor there are four apartments. Each apartment has one kitchen, one bathroom, one living room and three bedrooms. Approximately how many people live in Linda's building?

b) Which of the following facts could be important for finding the solution to the problem?

(You can tick more than one answer!)

$\mathrm{O}$ The house is 30 meters high.

O Roughly four people live in each apartment.

O There are two elevators.

O Each elevator can hold up to six people.

$\mathrm{O}$ There is one cellar for each apartment.

c) Which calculation could lead to finding an approximate solution to the question?

(You can tick more than one answer!)
O $8 \times 4 \times 4$
O $\quad 6 \times 30$
O $30+1$
O $4+2+6$
O $8 \times 4 \times 5$

d) Now work out the answer to the solution you ticked in c).

Following Bortz and Doering (2002, p. 214), for each of the five answer options, one point was given if it was answered correctly (ticked if correct and not ticked if false) and no point was given if the student answered incorrectly. Every student worked on four tasks with four different contents. To control the effect of task content and order, the sequence of tasks was controlled by applying a sequentially balanced Latin square.

\section{Covariates at student level}

As modeling competence might be affected by mathematical competence, we applied a standardized mathematics test (the German Mathematics Test DEMAT 4+; Goelitz, Roick, \& Hasselhorn, 2006). In addition, we expected cognitive abilities to affect modeling competence. Hence, fluid intelligence and crystallized intelligence were assessed using two scales of a German version of an intelligence scale (reasoning ability on matrix tasks for fluid cognitive abilities and scale thesaurus of words, meaning word comprehension, for crystallized cognitive abilities, see Weiss, 2006). Tests were applied only in the pretest as we did not expect any change in these cognitive abilities during the intervention.

\subsection{Analysis Strategy and Descriptive Statistics for Scales}

As we collected data of students and teachers both before and after the treatment, a multilevel approach with students at level one (within class-level) and teachers at level two (between class-level) is appropriate. This approach takes into account that data is nested (pupils are nested within classes).Variables at level one may vary within class, whereas values of variables at level two (e. g. teacher beliefs) are the same for all individuals in this class. Statistical modeling was carried out within the framework of multilevel structural equation modeling with 
Mplus version 6, using maximum likelihood estimation (Muthén \& Muthén, 2010). The advantage of multilevel structural equation modeling is the opportunity to test multiple path hypotheses simultaneously and further, to handle latent variables instead of observed variables, which takes the measurement error into account.

In order to construct indicator variables for the latent variables, the teacher belief scales were divided into an odd-numbered and an even-numbered item subscale (see below 3.8.). Descriptive statistics of scales for the total sample are summarized in table 2.

Table 2. Means and Standard Deviations (SD)

\begin{tabular}{llcccc}
\hline Level & & \multicolumn{2}{c}{ Pretest } & \multicolumn{2}{c}{ Posttest } \\
& & Mean & SD & Mean & SD \\
\hline Student & Modeling competence ${ }^{\mathrm{a}}$ & 3.30 & 0.52 & 3.50 & 0.52 \\
& Basic mathematical skills & 10.88 & 4.03 & & \\
& Logical reasoning & 7.49 & 2.91 & & \\
& Word comprehension & 14.98 & 5.53 & & \\
Teacher & Beliefs mathematics & & & & \\
& $\quad$ Usefulness odds & 2.85 & 0.51 & 2.73 & 0.56 \\
& $\quad$ Usefulness even & 3.18 & 0.57 & 3.17 & 0.43 \\
& Belief Learning/Teaching & & & & \\
$\quad$ Active Learner odds & 2.87 & 0.46 & 2.82 & 0.62 \\
$\quad$ Active Learner even & 2.42 & 0.54 & 2.57 & 0.52 \\
& Socio-constructivism & 3.08 & 0.45 & 3.13 & 0.48 \\
$\quad$ socio-constructivism odds & & & & \\
$\quad$ socio constructivism even & 3.41 & 0.43 & 3.42 & 0.32 \\
& Self-efficacy teaching & & & & \\
$\quad$ Teaching modeling odds & 3.13 & 0.47 & 3.38 & 0.41 \\
$\quad$ Teaching modeling even & 2.89 & 0.59 & 3.16 & 0.52 \\
\hline
\end{tabular}

Note: ${ }^{\text {a }}$ Sum score was computed without step four (mathematical solution).

For the basic mathematical skills scale (German mathematics test DEMAT) and the cognitive ability scale CFT-R (reasoning and word comprehension), reliabilities were higher than .70, according to the corresponding test manuals.

Regarding the competence scale of mathematical modeling, reliability was calculated before and after eliminating variables (in our study: steps of the modeling process) with low reliabilities according to the recommendations in classical test theory (Lienert \& Raatz, 1994, p. 95). In our study, the elimination of step four (finding a mathematical solution) led to an increased Cronbach's alpha of .60 for the pretest total competence scale (five items). Reliability of posttest scores was alpha $=.64$ (five items).

\subsection{Correlations between Scales}

The average class size was 17.76. Intercorrelations for the observed variables for within level (students) are presented in table 3. 
Table 3. Correlations between observed variables - within level (students)

\begin{tabular}{lllll}
\hline & 1 & 2 & 3 & 4 \\
\hline 2. Modeling post & .54 & & & \\
3. Math comp & .24 & .20 & & \\
4. Reasoning & .16 & .13 & .28 & \\
5. Word com & .27 & .21 & .23 & .36 \\
\hline
\end{tabular}

Note. 1 =modeling competence pretest, 2 = modeling competence posttest, $3=$ Basic mathematical skills, $4=$ nonverbal logical reasoning, 5 = word comprehension.

Between class correlations are summarized in table 4.

Table 4. Correlations between observed variables - between level (class)

\begin{tabular}{|c|c|c|c|c|c|c|c|c|c|c|}
\hline & 1 & 2 & 3 & 4 & 5 & 6 & 7 & 8 & 9 & 10 \\
\hline 2 & .46 & 1 & & & & & & & & \\
\hline 3 & .58 & .34 & 1 & & & & & & & \\
\hline 4 & .48 & .54 & .62 & 1 & & & & & & \\
\hline 5 & .17 & -.02 & .07 & .31 & 1 & & & & & \\
\hline 6 & .07 & -.23 & -.08 & -.07 & .54 & 1 & & & & \\
\hline 7 & .33 & .11 & .36 & .55 & .29 & .07 & 1 & & & \\
\hline 8 & .31 & .01 & .18 & .17. & .45 & .48 & .45 & 1 & & \\
\hline 9 & .06 & .09 & .11 & .20 & .44 & .14 & .13 & .28 & 1 & \\
\hline 10 & .07 & .24 & 0.16 & .25 & .38 & .11 & .03 & .10 & .51 & 1 \\
\hline 11 & .19 & .03 & .01 & .25 & .46 & .25 & .30 & .38 & .54 & .35 \\
\hline 12 & .15 & .14 & .13 & .28 & .36 & .03 & .15 & .33 & .37 & .39 \\
\hline 13 & .42 & .10 & .11 & .20 & .30 & .26 & .07 & .30 & .15 & .16 \\
\hline 14 & .28 & .16 & .04 & .13 & .33 & .38 & .09 & .38 & .30 & .19 \\
\hline 15 & .25 & .23 & .10 & .21 & .37 & .45 & .17 & .34 & .16 & .20 \\
\hline 16 & .25 & .21 & .10 & .18 & .29 & .38 & .12 & .33 & .09 & .16 \\
\hline 17 & -.11 & -.11 & -.06 & -.20 & -.16 & -.05 & -.21 & .18 & .09 & -.06 \\
\hline 18 & .12 & -.10 & .11 & .19 & .22 & .02 & .26 & .10 & .24 & .20 \\
\hline 19 & .20 & .09 & .07 & -.08 & -.17 & -.10 & .07 & -.18 & -.17 & -.05 \\
\hline 20 & .40 & .49 & .25 & .35 & .12 & -.02 & .37 & .12 & .18 & .14 \\
\hline 21 & .23 & .42 & .03 & .28 & .12 & -.15 & .11 & -.11 & -.11 & .06 \\
\hline 22 & .22 & .19 & .16 & 19 & .21 & .07 & .24 & .02 & -.02 & -.05 \\
\hline 23 & .28 & .34 & .01 & .33 & .27 & .01 & .15 & .05 & .28 & .42 \\
\hline
\end{tabular}

Correlations between observed variables - between level (class) - continuation

\begin{tabular}{rrrrrrrrrrrrr}
\hline & \multicolumn{1}{l}{11} & 12 & 13 & 14 & 15 & 16 & 17 & 18 & 19 & 20 & 21 & 22 \\
12 & .59 & 1 & & & & & & & & & & \\
13 & .38 & .37 & 1 & & & & & & & & \\
15 & .45 & .34 & .59 & 1 & & & & & & & \\
16 & .26 & .23 & .58 & .58 & 1 & & & & & & \\
17 & .07 & .28 & .33 & .45 & .80 & 1 & & & & & \\
18 & .30 & .02 & .02 & .27 & -.07 & -.04 & 1 & & & & \\
19 & -.25 & -.20 & .25 & -.09 & -.01 & -.04 & -.09 & -.50 & 1 & & & \\
20 & .35 & .23 & .07 & .15 & .05 & .04 & -.43 & .19 & 1 & & \\
21 & .15 & -.01 & .02 & .02 & .08 & .11 & -.51 & .25 & .78 & .46 & 1 & \\
22 & -.17 & -.17 & .05 & -.05 & .27 & .08 & -.61 & .09 & .60 & .48 & .67 & 1 \\
23 & .32 & .06 & .26 & .13 & .06 & -.12 & -.33 & .17 & .51 & .52 & .61 & .34 \\
\hline
\end{tabular}

Note. 1 = usefulness odds (pre), 2 = usefulness even (pre), 3 = usefulness odds (post), 4 = usefulness even (post), $5=$ role of learner as active odds (pre), $6=$ role of learner as active even (pre), $7=$ role of learner as active odds (post), $8=$ role of learner as active even (post), $9=$ socio-constructivism odds (pre), $10=$ socio-constructivism even (pre), 11 = socio-constructivism odds (post), 12 = socio-constructivism even (post), 13 = self-efficacy odds (pre), 14 = self-efficacy even (pre), 15 = self-efficacy odds (post), 16 = self-efficacy even (post), 17 = dummy written, 18 = dummy both, 19 = modeling competence (pre), 20 = modeling competence (post), 21 = basic mathematical skills, 22 = logical reasoning, 23 = word comprehension 


\subsection{Between Class Level: Measurement Models of Teacher Beliefs}

At the teacher level, beliefs were treated as latent variables for each of the measurement points. In order to construct indicators for these latent variables, each belief scale was divided into an odds/even subscale consisting of odd-numbered items and even-numbered ones. By doing so, we were able to test relationships between latent variables and thereby accounted for the measurement error. The latent variable beliefs about mathematics was indicated by the odds-subscale and the even-subscale "usefulness of mathematics." The latent variable beliefs about learning was indicated by four subscales: odds-subscale und even-subscale "role of learner as active" and odds-subscale and even-subscale "socio-constructivism." Indicators for the latent variable "self-efficacy in teaching modeling" were odds-subscale and even-subscale of the corresponding self-efficacy scale. Standardized factor loadings for these scales are summarized in table 5.

The composite reliabilities (Bacon, Sauer \& Young, 1995) of the latent variables were calculated based on the data of the final model (see below): beliefs mathematics pretest $=.63$, beliefs mathematics posttest $=.76$, learning/teaching beliefs pretest $=.67$, learning/teaching beliefs posttest $=.72$, self-efficacy belief pretest $=.91$, self-efficacy beliefs posttest $=.77$.

Table 5. Measurement model - teacher beliefs (standardized parameter estimates)

\begin{tabular}{llcc}
\hline Latent Variable & Indicator & Pretest & Posttest \\
\hline Teacher beliefs mathematics & Usefulness odds ${ }^{\text {a }}$ & .70 & .73 \\
& Usefulness even & .66 & .84 \\
Teacher belief learning/teaching & Active learner odds ${ }^{\text {a }}$ & .78 & $.38^{\mathrm{b}}$ \\
& Active learner even & .53 & .57 \\
& Socio-constructivism odds & .52 & .86 \\
& Socio-constructivism even & .50 & .67 \\
Teacher self-efficacy & Self-efficacy odds ${ }^{\text {a }}$ & 1.04 & .77 \\
& Self-efficacy even & .78 & .82 \\
\hline
\end{tabular}

Note. ${ }^{\mathrm{a}}$ Factor loading was fixed to one. ${ }^{\mathrm{b}} p<.01$, all other factor loadings $p<.001$.

\section{Results}

In the following, we first outline the pre-test differences at individual and class levels. We used these results to determine which variables had to be statistically controlled as covariates. Then we go on to explain how we transformed the hypotheses into a structural equation model at teacher (class) level and at student level (within class level). Finally, we depict how this structural equation model (which represents the hypotheses) fits to the data and which parameter estimates support the hypotheses.

\subsection{Pretest Differences at Student Level (within Class) and Teacher Level (between Class)}

In order to identify pretest differences between the control group and the two intervention groups, a multivariate analysis of variance with three groups (control group, written material, written material plus teacher training) as independent variables and the students' modeling competence, reasoning ability, word comprehension and basic mathematical skills as dependent variables was performed. The multivariate statistics Wilk's lambda was .97 and indicated significant overall differences between the three groups $(F(8,1906)=3.65, p<.001)$. For all dependent variables, univariate analyses of variance yielded significant differences between the three groups. Therefore, these pretest scores had to be included as covariates in the structural model (see below). As differences in these variables between treatment groups occurred, correlations between these covariables and dummy variables (which indicate treatment contrasts) were estimated in the theoretical model (see section 4.2.). Estimating these correlations in the theoretical model considers the fact that treatment membership was not independent from values in the covariables.

Similarly, an analysis of variance at class level with the three groups as independent variable and teacher manifest belief subscales as covariates was carried out. The multivariate Wilk's lambda was .68 $(F(16,88)=$ $1.19, p=.29$ ). Despite the non-significant overall effect, univariate analyses yielded a significant difference for one of the indicators (socio-constructivist view, odds-scale). Therefore, a correlation between this indicator and 
treatment indicator variables was allowed for in the structural model (see below). However, teachers did not differ in age, number of completed enhanced teacher training sessions, motivation to complete questionnaires or motivation to take part in the study.

\subsection{Transforming the Hypotheses into a Structural Equation Model}

In order to test the hypotheses, a two-level structural equation model was specified (Muthén \& Muthén, 2010). By following a two-level approach, we considered that data is nested (level one: within class level, students; and level two: between class level, class means or teachers). For all students within one class, the same values in between class variables apply (e. g. teacher belief scores). Regarding within class-variables (e. g. fluid intelligence), however, students may differ within one class. Within the multilevel framework, we specified a model similar to an analysis of covariance approach, taking pretest scores, treatment group and relevant covariables as covariates. This strategy is appropriate in the analysis of pre and post control group designs (Dugard \&Todman, 1995).

\subsubsection{Between Level Structural Equation Model (between Class, Teacher)}

At class level (between level), the three groups (materials plus training, materials, control) were indicated by two dummy variables. The first dummy variable "written vs. control" was assigned value 1 for the group which received the written materials, otherwise it was assigned 0 . The second dummy variable "both vs. control" was assigned value 1 for the group which received written materials and one-day training, otherwise it was assigned 0 . These dummy variables specify the contrast between control group vs. the group with written materials, and the contrast between control group and the group written material plus one-day training.

A direct path was specified from each of the dummy variables to student modeling competence at class level. These paths correspond to the hypothesis that posttest class means of student modeling competence in intervention classes will be higher than posttest class means of the control group (Hypothesis 1).

From the two dummy variables, paths were specified to three latent teacher posttest beliefs (mathematics beliefs, learning beliefs, self-efficacy beliefs). These paths represent Hypothesis 2 (effect of intervention on teacher posttest beliefs). From each of the posttest teacher latent beliefs, a path was specified indicating the impact of this latent teacher belief about student modeling competence at class level. By specifying these paths, the indirect effect of intervention on posttest student competences via teacher beliefs could be tested (Hypothesis 3).

Each of the three latent teacher beliefs in the pretest and the class means of student modeling competence in the pretest were taken as covariates at class level. As the other student covariates basic mathematical skills, reasoning ability (fluid intelligence) and word comprehension also differed between the three groups, these covariates were taken into account as covariates at class level, and correlations between these covariates - as well as correlations between these covariates and the dummy variables - were added into the model. As pretest differences in one of the indicators of teacher learning beliefs existed (differences in odds scale socio-constructivist view), correlations between this indicator subscale and the two dummy variables were included. Furthermore, correlations were admitted between the three latent beliefs at pretest and between the three latent beliefs at posttest.

\subsubsection{Within Level Structural Equation Model (Student)}

At the individual level (within level), posttest modeling competence was regressed on pretest scores by adding a path from pretest modeling competence to posttest modeling competence. Paths were also added from basic mathematics skills and from the reasoning scale (fluid intelligence as measured by matrices tasks) and the word comprehension scale (crystallized intelligence) to posttest modeling competence. Correlations between pretest modeling competence, basic mathematical skills and the two cognitive ability scales were included. The complete theoretical model is illustrated in Figure 2.

\subsubsection{Overall Fit of the Structural Equation Model}

The overall model fit was acceptable (chi-square $(197, N=959)=282.11, d f=197, p=.0001$; CFI $=.92$, RMSEA = 0.021). However, the model fit for the within-model was considerably better than for the between-model (SRMR for between $=0.15$, SRMR value for within $=0.001$ ). The intraclass correlation (percentage of total variance due to variance between classes) for posttest variables was low (ICC $=.05$ for pretest modeling competence, .04 for posttest modeling competence, .08 for mathematical competence, .04 for fluid cognitive abilities and .07 for crystallized cognitive abilities). 


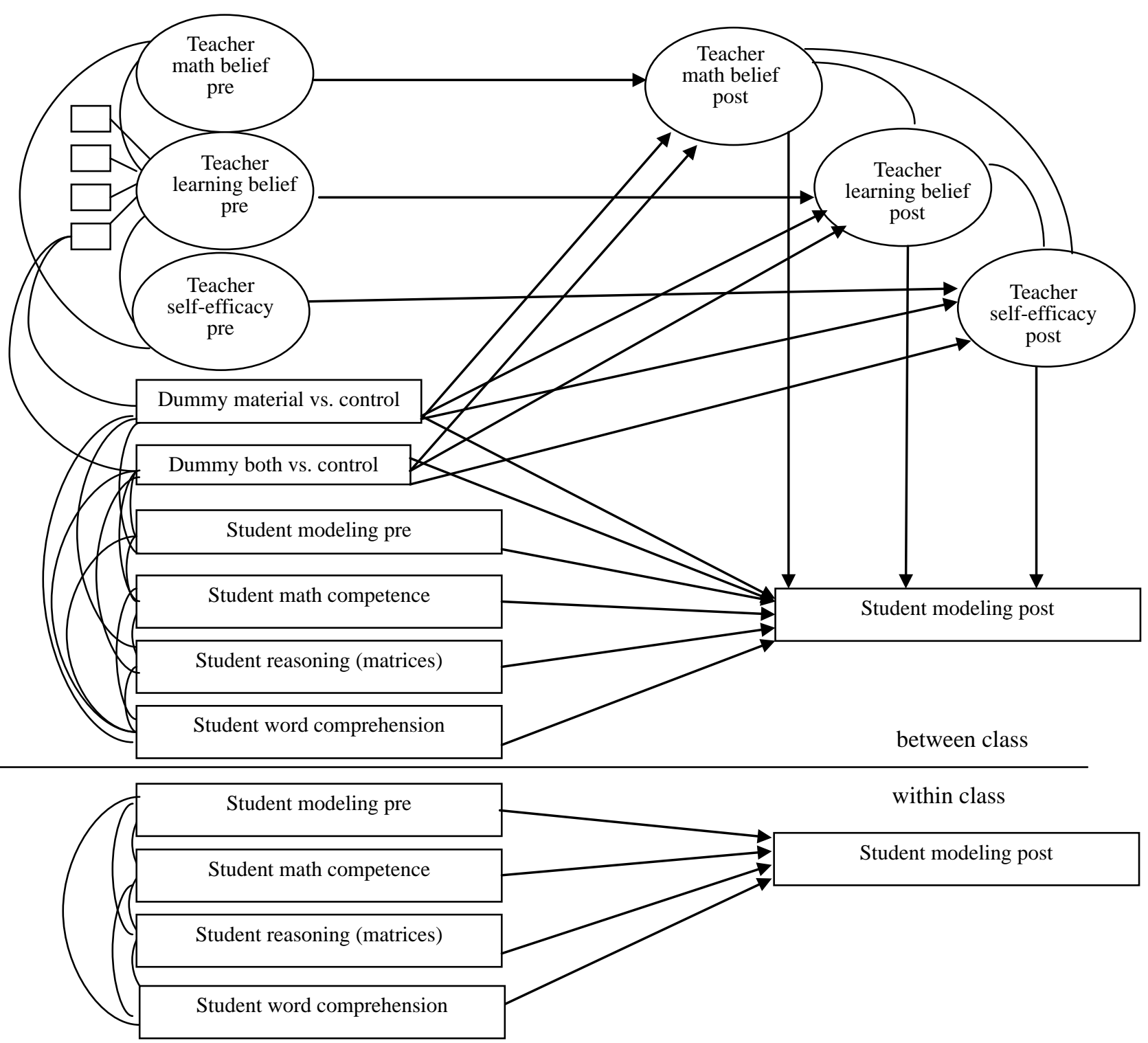

Figure 2. Theoretical multilevel path model

Note . Pre $=$ pretest, post $=$ posttest, dummy written vs. control $=$ dummy variable written material vs. control, dummy both vs. control = dummy variable written material and one day training vs. control.

\subsubsection{Parameter Estimates Results}

The standardized parameter estimates are presented in Figure 3. For reasons of lucidity, non-significant paths and non-significant correlations were omitted. 


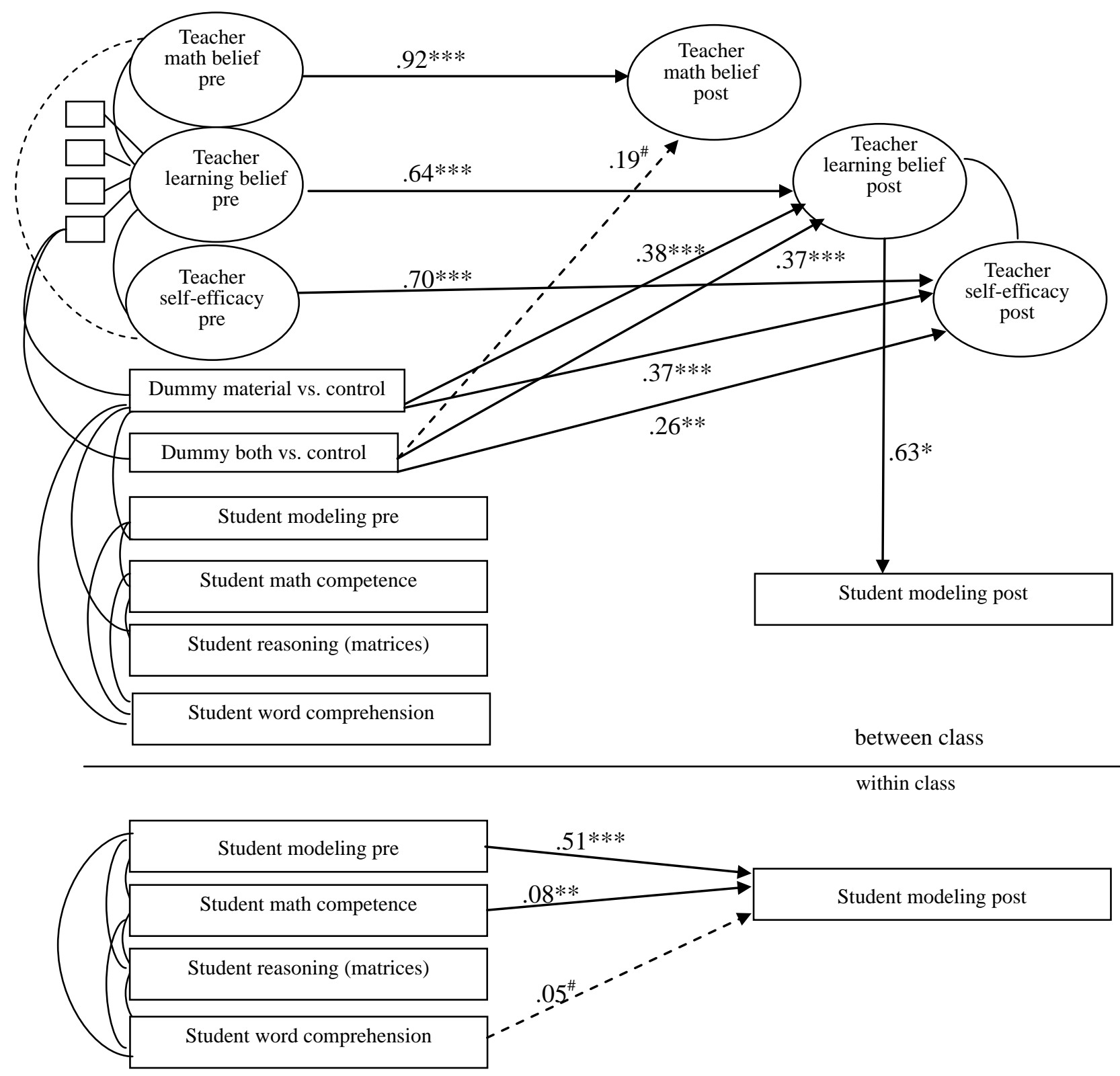

Figure 3. Standardized estimates of the multilevel path model

Note . Pre $=$ pretest, post $=$ posttest, dummy written vs. control $=$ dummy variable written material vs. control, dummy both vs. control = dummy variable written material and one-day training vs. control, dashed line: path coefficients with $\mathrm{p}<.10$ (one tailed). ${ }^{\#} p<.10,{ }^{*} p<.05,{ }^{* *} p<.01,{ }^{* * *} p<.001$ (one-tailed).

\section{Between Class Level Results}

At class level (between level), no direct paths from the two dummy variables indicating contrasts of treatment versus control group to posttest student modeling competence could be confirmed. That means that the intervention did not directly affect student modeling competence (no statistical difference in class means between intervention classes and control classes). However, paths from both dummy variables to teacher learning beliefs and to teacher self-efficacy (posttest) could be affirmed. In other words: When pretest beliefs were statistically controlled as covariates, an effect of the intervention was detectable for teacher learning beliefs and self-efficacy beliefs (higher posttest scores of teachers in the intervention groups as indicated by positive parameter estimates). However, the intervention had almost no effect on teacher mathematics beliefs. 
Interindividual stability of these latent teacher beliefs was indicated by highly significant stability coefficients (parameter estimates) from each pretest teacher belief to the corresponding posttest teacher belief. Interindividual stability of teacher mathematics beliefs appeared to be particularly high. The corresponding standardized parameter estimate of .92 indicated that an increase of one standard deviation unit in pretest beliefs covaries with an increase of $0.92 \mathrm{x}$ one standard deviation unit in posttest beliefs. This means that teachers who believed that mathematics is useful in the pretest still held this opinion at the posttest (and correspondingly for teachers with lower values).

Student posttest modeling competence (class means) could only be predicted by teacher posttest learning beliefs (when teacher pretest learning beliefs were statistically controlled). An increase in teacher posttest learning beliefs of one standard deviation unit on average led to an increase of student posttest class means of modeling competence of $0.63 \mathrm{x}$ one standard deviation unit.

Summarizing the parameter estimates at between levels, both intervention groups (when compared to the control group) fostered teacher learning beliefs and self-efficacy beliefs, whereas only teacher posttest learning beliefs (constructivist and socio-constructivist view) enhanced student modeling competence. These relationships remained true when pretest teacher beliefs and pretest class means of student modeling competence were statistically controlled.

\section{Within Class Level Results}

Regarding results at student level (within level), posttest modeling competence was affected primarily by pretest modeling competence, by basic mathematical skills and, to a lesser degree, by crystallized cognitive abilities. Fluid cognitive abilities, however, did not affect posttest modeling competence.

Hence, Hypothesis 1 (higher scores of posttest modeling competence in intervention groups) was rejected, whereas Hypothesis 2 (effect of the intervention on teacher beliefs) could be confirmed. The implementation of the curriculum materials affected teacher (socio-) constructivist learning beliefs as well as teacher self-efficacy beliefs. In addition, teacher constructivist learning beliefs had an effect on student modeling competence, which confirmed Hypothesis 3 in regards to learning beliefs. However, when it comes to teacher beliefs about mathematics, Hypotheses 2 and 3 could not be confirmed (no effect of curriculum materials on these beliefs). Moreover, self-efficacy beliefs could be fostered by the intervention, but did not affect student modeling competences.

Apart from the non-significant effect of fluid cognitive abilities (assessed in matrices tasks), Hypothesis 4 could be confirmed, as basic mathematical skills and crystallized intelligence (word comprehension) influenced posttest modeling competence.

For the paths from each of the intervention groups (materials only, materials plus one-day-training) to the latent variable of teacher beliefs, comparable regression coefficients were estimated (.38 vs. .37). This result indicates that regarding the effects on teacher beliefs it made no difference whether teachers obtained materials only or materials plus a one-day teacher training introducing the use of the materials.

\section{Discussion}

\subsection{Discussion from an Educational Perspective}

The aim of this study was to test the effectiveness of teaching materials about mathematical modeling on student learning outcomes and the role of teacher beliefs for the effectiveness of the materials.

In order to evaluate the effects, we simultaneously considered effects on student achievement and on teacher beliefs in a quantitative, multilevel framework. Results showed that the effect of simply letting students work on specially designed modeling tasks does not directly promote their modeling competence (no significant path from intervention dummy variables to student posttest competence scores). Instead, the student competences were affected by an increase in their teachers' constructivist beliefs. The more teachers developed a constructivist and socio-constructivist view of teaching from pretest to posttest, the higher the increase in student competence in mathematical modeling was. These results are in line with other results affirming the effect of teacher beliefs about teaching and learning on learning outcomes (Staub \& Stern, 2002). In consequence, our study confirms the effect of curriculum materials on student modeling competences - if these materials affect teacher beliefs about learning and teaching. This mediation effect of teacher beliefs on student learning outcomes has direct implications for teacher education and teacher training which should foster constructivist and socio-constructivist beliefs of prospective and present mathematics teachers.

The results of our study further show that the beliefs about learning were of lower stability than beliefs about 
mathematics or efficacy beliefs, and are obviously to a higher degree amenable to influence. The high stability of beliefs about mathematics in this study also supports previous research which revealed a high stability of teacher beliefs (Milner, 2005; Turner, Christensen \& Meyer, 2009). Apparently, beliefs about mathematics seem to be harder to change than beliefs about teaching and learning of mathematics. Thus, the beliefs about mathematics might be more peripheral than the others (Furenghetti \& Pehkonen, 2002).

It seems likely that the coherence of beliefs and the underlying concepts of curriculum materials (e.g. the constructivist concepts of our materials) may be crucial for the effectiveness of the implemented materials (McDuffie \& Marther, 2006; Tillema, 1995).

The low intraclass correlations indicate that only a part of the variance in student modeling competence is due to differences between classes and thus, teachers. More concretely, only a part of student learning outcomes is related to the teachers and their beliefs. A major role is also played by student individual factors. Other studies support the relevance of individual factors compared to class level factors (Helmke \& Schrader, 2001). In line with these studies, the present study specifies the relevance of individual (within class) factors for the competence in mathematical modeling: Apart from basic mathematical skills, word comprehension (crystallized intelligence) seems to have a certain effect on modeling competence. If we consider the modeling process (see Figure 1), this result seems plausible. The first step (understanding the instructions), the second step (constructing a real model), the fifth step (interpreting the solution) and sixth step (validating) all demand general knowledge, verbal comprehension and crystallized cognitive abilities (Mischo \& Maaß, in press).

With respect to the impact of an additional one-day teacher training, we did not find substantial differences between the two intervention groups. This means that an additional one-day teacher training in order to introduce the materials had no incremental effect on teacher change in beliefs or student competence gains. Our results are therefore in line with findings from research which suggest long-term interventions (e. g. Lipowsky, 2004). This study also indicates that one-day courses, even when tailored to facilitate the use of materials, do not have an incremental effect as compared to merely handing out the materials.

\section{Limitations of the Study}

The resources available for this study meant that no classroom observation could be conducted. Therefore, we cannot present information about the way teacher beliefs affected their classroom behavior and the concrete implementation of the materials. We had to rely on the information provided by the teachers about whether they had implemented the materials as recommended. In the future, additional qualitative and observational analyses should be conducted in order to investigate the relationship between change in learning beliefs and change in instructional behavior.

As the present study was not a laboratory study, but an intervention in day-to-day teaching, we could not control what teachers did in mathematics classes when not using the materials. Only observational studies may provide insight into the lessons held by teachers, and such a study would have exceeded our existing financial and personnel resources.

However, a point for discussion might be whether it would be more meaningful to carryout a 13-day, laboratory study in which teachers only teach mathematical modeling - or conduct a one year study in day-to-day teaching in which modeling units are implemented regularly. The former does seem to be ecologically valid while the latter may bring problems for internal validity (Shadish, Cook \& Campbell, 2002). In the present quasi-experimental design, we decided in favor of ecological (external) validity and tried to control confounding variables statistically at the student and teacher level.

In addition, the low reliability of the measurement of modeling competence has to be considered (alpha about .60). Modeling competence is a complex construct with different steps according to the modeling cycle. Step four, which refers to mathematical computation, turned out to be of low reliability. Other analyses support the interpretation that this step in the modeling cycle is not a reliable indicator for the sum score of modeling competence (Mischo \& Maaß, in press). The low reliability of the sum score of modeling competence demonstrates the so called "bandwidth-fidelity dilemma" (Cronbach, 1961). This means that the broader the construct, the lower the reliability of its measures. Relatively low internal consistency was also calculated for conceptually related, complex constructs such as problem solving competence assessed in the PISA study in Germany (Klieme, Funke, Leutner, Reimann, \& Wirth, 2001) or systems thinking (Riess \& Mischo, 2009). Thus, when accounting for the complexity of the theoretical construct, lower internal consistency can be considered as acceptable and in consequence, the reliability of our measurement is in line with other research. Nonetheless, further research should address the question of how to measure this construct. 
Summing up, the results are in line with the growing evidence for the relevance of teacher beliefs for the implementation of curriculum materials and for the effect on student outcomes. Our findings concur with the reasoning of Pajares (1992) that teacher beliefs filter perception, and motivate and regulate teacher actions. However, our study expands on this by providing additional information about which kind of teacher beliefs and which student individual factors have an incremental effect on student outcomes in mathematical modeling.

Therefore, the results of the present quantitative study in the framework of multilevel structural equation modeling are in line with, but also exceed and quantitatively specify results from previous, more qualitative studies. Coming back to the aim of facilitating a widespread implementation of mathematical modeling, the study also shows that it is helpful to provide teachers with appropriate curriculum materials as these materials have an effect on student learning outcomes - when teachers adopt a (socio-) constructivist view of mathematics education. From an educational point of view, promoting change in teacher constructivist beliefs may be a crucial point in improving instructional practice and thereby enhance educational opportunities, especially that of low performing students.

\section{References}

Aldridge, J. M., Fraser, B. J., Taylor, P. C., \& Chen, C. C. (2000).Constructivist learning environments in a cross-national study in Taiwan and Australia.International Journal of Science Education, 22, 37-55. http://dx.doi.org/10.1080/095006900289994

Angantysdottir, G. (2010). Professional development: How did teachers' participation in the professional development program influence their teaching practice? In B. Sriraman, C. Bergsten, S. Goodchild, G. Palsdottir, B. Dahl \& L. Haapasalo (Eds.), The first sourcebook on Nordic research in mathematics education (pp. 505-518). Greenwich, C. T.: IAP Information Age Publishing.

Bacon, D. R., Sauer, P. L., \& Young, M. (1995). Composite reliability in structural equation modelling. Educational and Psychological Measurement, 55, 394-406. http://dx.doi.org/10.1177/0013164495055003003

Bandura, A. (1997). Self-efficacy: The exercise of control. New York: Freeman.

Baumert, J., Kunter, M., Brunner, M., Krauss, S., Blum, W., \& Neubrand, M. (2004). Mathematikunterricht aus Sicht der PISA-Schülerinnen und -Schüler und ihrer Lehrkräfte. [Mathematics lessons from the point of view of PISA pupils and their teachers]. In DeutschesPISA-Konsortium (Ed.), PISA 2003 - Der Bildungsstand der Jugendlichen in Deutschland - Ergebnisse des zweiten internationalen Vergleichs. [PISA 2003 - Educational levels of young people in Germany - Results of the second international comparison] (pp. 314-354). Opladen: Leske\&Budrich.

Baumert, J., \& Schümer, G. (2001). Familiäre Lebensverhältnisse, Bildungsbeteiligung und Kompetenzerwerb. [Family living conditions, educational participation and the acquisition of competences.] In Deutsches PISA-Konsortium (Ed.), PISA 2000 - Basiskompetenzen von Schülerinnen und Schülern im internationalen Vergleich [Basic competencesofpupilscomparedinternationally] (pp. 323-407). Opladen: Leske \& Budrich. http://dx.doi.org/10.1007/978-3-322-83412-6_10

Blum, W., \& Alsina, C. (2002). ICMI Study 14: Applications and Modelling in Mathematics Education Discussion Document. Educational Studies in Mathematics, 51, 149-171. http://dx.doi.org/10.1007/BF02655826

Blum, W., \& Leiss, D. (2005). Modellieren im Unterricht mit der „Tanken“-Aufgabe [Modeling in class with the "Refueling” task.]. Mathematik Lehren, 128, 18-21.

Blum, W., Neubrand, M., Ehmke, T., Senkbeil, M., Jordan, A., Ulfig, F., et al. (2004). Mathematische Kompetenz. [Mathematicalcompetence.] In Deutsches PISA-Konsortium (Ed.), PISA 2003 - Der Bildungsstand der Jugendlichen in Deutschland - Ergebnisse des zweiten internationalen Vergleich (pp. 47-92). Münster: Waxmann.

Borromeo-Ferri, R. (2007). Modelling problems from a cognitive perspective. In C. Haines, P. Galbraith, W. Blum \& S. Khan (Eds.), Mathematical modelling - Education, Engineering and Economics (pp. 260-270). Chichester: Horwood Publishing Limited.

Bortz, J., \& Doering, C. (2002). Forschungsmethoden und Evaluation. [Research methods and evaluation].Berlin, Heidelberg: Springer.

Burkhardt, H. (2006). Modelling in mathematics classrooms: Reflections on past development and the future. Zentralblatt für Didaktik der Mathematik, 38(2), 178-195. http://dx.doi.org/10.1007/BF02655888 
Cai, J., Kaiser, G., Perry, B., \& Wong, N. Y. (Eds.). (2009). Effective Mathematics Teaching from Teachers' Perspectives: National and Cross-National Studies. Rotterdam: Sense Publisher. http://dx.doi.org/10.1007/978-3-8348-2389-2_30

Caprara, G. V., Barbaranelli, C., Steca, P., \& Malone, P. S. (2006). Teachers' self-efficacy beliefs as determinants of job satisfaction and students' academic achievement: A study at the school level. Journal of School Psychology, 44, 473-490. http://dx.doi.org/10.1016/j.jsp.2006.09.001

Cattell, R. B. (1971). Abilities: Their structure, growth, and action. New York: Houghton Mifflin.

Cobb, P., Wood, T., \& Yackel, E. (1990). Classrooms as learning environments for teachers and researchers. In R. B. Davis, C. A. Maher \& N. Noddings (Eds.), Journal for Research in Mathematics education: Constructivists views on the teaching and learning of mathematics (Vol. 4, pp. 125-146). Reston, VA: National Council of Teachers of Mathematics. http://dx.doi.org/10.2307/749917

Dionne, J. J. (1984). The perception of mathematics among elementary school teachers. Paper presented at the Conference of the North American Chapter of the International Group for the Psychology of Mathematics Education (PME-NA), Madison, University of Wisconsin.

Doorman, M., Drijvers, P., Dekker, T., van den Heuvel-Panhuizen, M., de Lange, J., \& Wijers, M. (2007). Problem solving as a challenge for mathematics education in The Netherlands.Zentralblatt für Didaktik der Mathematik, 39(6), 405-418. http://dx.doi.org/10.1007/s11858-007-0043-2

Dubberke, T., Kunter, M., McElvany, N., Brunner, M., \& Baumert, J. (2008). Lerntheoretische Überzeugungen von Mathematiklehrkräften: Einflüsse auf die Unterrichtsgestaltung und den Lernerfolg von Schülerinnen und Schülern [Learning beliefsofmathematicsteachers: impact on lessonsandlearningoutcomesofpupils]. Zeitschrift für Pädagogische Psychologie, 22, 193-206. http://dx.doi.org/10.1024/1010-0652.22.34.193

Dugard, P., \& Todman, J. (1995). Analysis of pretest posttest control group designs in educational research. Educational Psychology, 15, 181-99.

Eynde, P. O. t., De Corte, E., \& Verschaffel, L. (2002). Framing students' mathematics-related beliefs. In G. Leder, E. Pehkonen\& G. Törner (Eds.), Beliefs: A hidden variable in mathematics education? (pp. 13-37). Dordrecht: Kluwer Academic Publishers. http://dx.doi.org/10.1007/0-306-47958-3_9

Furinghetti, F., \& Pehkonen, E. (2002). Rethinking characterisations of beliefs. In G. Leder, E. Pehkonen, \& G. Törner (Eds.), Beliefs: A hidden variable in mathematics education? (pp. 39-57). Dordrecht: Kluwer Academic Publishers. http://dx.doi.org/10.1007/0-306-47958-3_9

Galbraith P, \& Clatworthy, N. (1990). Beyond standard models-meeting the challenge of modelling. Educational Studies in Mathematics, 21, 137-163. http://dx.doi.org/10.1007/BF00304899

Goelitz, D., Roick, T., \& Hasselhorn, M. (2006). Deutscher Mathematiktest für vierte Klassen (DEMAT 4) [GermanMathematics Test forthefourth grade]. Göttingen: Hogrefe.

Grigutsch, S., Raatz, U., \& Törner, G. (1998). Einstellungen gegenüber Mathematik bei Mathematiklehrern [Beliefsaboutmathematicsofmathematicsteachers]. Journal fürMathematik-Didaktik, 19, 3-45.

Gunnarsdottir, G. H., \& Palsdottir, G. (2010). The implementation of the intended curriculum in teaching materials: Authors' perspective. In B. Sriraman, C. Bergsten, S. Goodchild, G. Palsdottir, B. Dahl \& L. Haapasalo (Eds.), The first sourcebook on Nordic research in mathematics education (pp. 539-549). Greenwich, C. T.: IAP Information Age Publishing.

Haines, C., Crouch, R., \& Davies, J. (2001). Understanding students’ modelling skills. In J. F. Matos, W. Blum, K. Houston \& S. P. Carreira (Eds.), Modelling and Mathematics Education, ICTMA 9: Applications in Science and Technology (pp. 366-380). Chichester: Horwood Publishing.

Heck, R. H. (2009). Teacher effectiveness and student achievement: Investigating a multilevel cross-classified model. Journal of Educational Administration, 47, 227-249. http://dx.doi.org/10.1108/09578230910941066

Helmke, A., \& Schrader, F. W. (2001). School achievement, cognitive and motivational determinants. In N.J. Smelser\& P.B. Baltes (Eds.), International Encyclopedia of the Social and Behavioral Sciences, Vol. 20 (pp. 13552 - 13556). Oxford: Elsevier. http://dx.doi.org/10.1016/B0-08-043076-7/02413-X

Helmke, A., \& Schrader, F. W. (2006). Determinanten der Schulleistung [Determinants of school learning]. In D. Rost (Ed.), Handwörterbuch Pädagogische Psychologie [Handbook Educational Psycholog] (pp. 83-94). Weinheim: Beltz Psychologie Verlags Union. 
Kaasila, R., Hannula, M., Laine, A., \& Pehkonen, E. (2006). Facilitators for change of elementary teacher student's view of mathematics. In J. Novotaná, H. Moraová, M. Krátká, \& N. Stehliková (Eds.), Proceedings 30th Conference of the International Group for the Psychology of Mathematics Education (Vol. 3, pp. 385-392). Prague: PME.

Kaiser, G., \& Sriraman, B. (2006). A global survey of international perspectives on modelling in mathematics education. Zentralblatt für Didaktik der Mathematik, 38, 302-310. http://dx.doi.org/10.1007/BF02652813

Klieme, E., Funke, J., Leutner, D., Reimann, P., \& Wirth, J. (2001). Problemlösen als fächerübergreifende Kompetenz[Problem solvingascross curricular competence]. Zeitschrift für Pädagogik, 47, 179-200.

Klieme, E., Neubrand, M., \& Luedtke, O. (2001). Mathematische Grundbildung: Testkonzeption und Ergebnisse. [Basic education in mathematics: Test conceptandresults]. In Deutsches PISA-Konsortium (Ed.), PISA 2000 - Basiskompetenzen von Schülerinnen und Schülern im internationalen Vergleich [Basic competencesofpupilscomparedinternationally] (pp. 139-190). Opladen: Leske \& Budrich. http://dx.doi.org/10.1007/978-3-322-83412-6_5

Little R. J A. (1988). A test of missing completely at random for multivariate data with missing values.Journal of American Statistical Association, 83, 1198-1202. http://dx.doi.org/10.2307/2290157

Maßß, K. (2006). What aremodelling competencies? Zentralblatt für Didaktik der Mathematik, 38(2), 113-142. What are modelling competencies? http://dx.doi.org/10.1007/BF02655885

Maaß, K. (2010). Classification scheme of modelling tasks. Journal für Mathematik-Didaktik, 31(2). http://dx.doi.org/10.1007/s13138-010-0010-2

Maaß, K., \& Mischo, C. (2011). Implementing Modelling into Day-to-Day Teaching Practice - The Project Strategies on teaching and understanding in and through modeling (STRATUM) and its Framework. Journal für Mathematik-Didaktik, 32(1). http://dx.doi.org/10.1007/s13138-010-0015-x

McDuffie, A. M., \& Mather, M. (2006). Reification of instructional materials as part of the process of developing problem-based practices in mathematics education. Teachers and Teaching: theory and practice, 12, 435-459.

Milner, H. R. (2005). Stability and change in prospective teachers' beliefs and decisions about diversity and learning to teach. Teaching and Teacher Education, 21(7), 767-786.

Mischo, C., \& Maaß, K. (in press). Which personal factors affect mathematical modelling? The effect of abilities, domain specific and cross domain-competences and beliefs on performance in mathematical modelling. Journal of Mathematical Modelling and Application.

Muthén, L. K. \& Muthén, B. (2010). Mplus Version 6. Statistical Analysis with Latent Variables. Los Angeles, CA: Muthén \& Muthén.

Pajares, M. F. (1992). Teachers' beliefs and educational research: Cleaning up a messy construct.Review of Educational Research, 62, 307-332. http://dx.doi.org/10.2307/1170741

Pehkonen, E., \& Törner, G. (1996). Mathematical beliefs and different aspects of their meaning. Zentralblatt für Didaktik der Mathematik, 28(4), 101-108.

Prawat, R. S. (1992). Teachers' beliefs about teaching and learning: A constructivist perspective. American Journal of Education, 100(3), 354-395.

Richardson, V., \& Placier, P. (2001). Teacher change.In V. Richardson (Ed.), Handbook of research in teaching (pp. 905-947). Washington, D. C.: American Educational Research Association.

Riess, W., \& Mischo, C. (2009). Promoting systems thinking through biology lessons. Journal of Research in Science Teaching, 42, 518-560. http://dx.doi.org/10.1080/09500690902769946

Ross, J. A. (1998). The antecedents and consequences of teacher efficacy. In J. Brophy (Ed.), Advances in research on teaching, Vol. 7 (pp. 4974).Greenwich, CT: JAI Press.

Ross, J. A., McDougall, D., Hogaboam-Gray, A., \& LeSage, A. (2003). A survey measuring elementary teachers' implementation of standards-based mathematics teaching. Journal for Research in Mathematics Education, 34(4), 344-363. http://dx.doi.org/10.2307/30034787

Ruthven, K. (1987). Ability stereotyping in mathematics.Educational Studies in Mathematics, 18, 243-253. http://dx.doi.org/10.1007/BF00386197

Schmitz, G. S., \& Schwarzer, R. (2000). Selbstwirksamkeitserwartung von Lehrern: Längsschnittbefunde mit 
einem neuen Instrument [Self-efficacyexpecationsofteachers: resultswith a newinstrument]. Zeitschrift für Pädagogische Psychologie, 14, 12-25. http://dx.doi.org/10.1024//1010-0652.14.1.12

Schoen, H., Cegulla, K., Finn, K., \& Fi, C. (2003). Teacher variables that relate to student achievement when using a standards-based curriculum. Journal for Research in Mathematics Education, 34(3), 228-259. http://dx.doi.org/10.2307/30034779

Schoenfeld, A. (1992). Learning to think mathematically: Problem solving, metacognition and sense-making in Mathematics. In D. Grouws (Ed.), Handbook for Research on mathematics teaching and learning (pp. 334-370). New York.

Shadish, W. R., Cook, T. D., \& Campbell, D. T. (2002). Experimental and Quasi-Experimental Designs for Generalized Causal Inference. New York: Houghton Mifflin Company.

Shulman, L. (1986). Those who understand: Knowledge growth in teaching. Educational Researcher, 15, 4-14. http://dx.doi.org/10.2307/1175860

Staub, F. C., \& Stern, E. (2002). The nature of teachers' pedagogical content beliefs matters for students' achievement gains: Quasi-experimental evidence from elementary mathematics. Journal of Educational Psychology, 94, 2, 344-355. http://dx.doi.org/10.1037//0022-0663.94.2.344

Stein, M., Smith, M., Henningsen, M., \& Silver, E. (2000). Implementing standards-based mathematics instruction: a casebook for professional development. New York: Teachers College Press.

Stipek, J. S., Givvin, K. B., Salmon, J. M., \& MacGyvers, V. L. (2001). Teachers’ beliefs and practices related to mathematics instruction. Teaching and Teacher Education, 17, 213-226. http://dx.doi.org/10.1016/S0742-051X(00)00052-4

Taylor, P. C., Fraser, B. J., \& Fisher, D. L. (1997). Monitoring constructivist classroom learning environments. International Journal of Educational Research, 27, 293-302. http://dx.doi.org/10.1016/S0883-0355(97)90011-2

Tillema, H. H. (1995). Changing the professional knowledge and beliefs of teachers: A training study. Learning and Instruction, 5, 291-318. http://dx.doi.org/10.1016/0959-4752(95)00020-8

Törner, G. (2002). Epistomologische Grundüberzeugungen - verborgende Variablen beim Lehren und Lernen von Mathematik. [Fundamental epistemological beliefs - Hidden variables in teaching and learning of mathematics]. Der Mathematikunterricht, 4-5, 103-128.

Turner, J. C., Christensen, A., \& Meyer, D. M. (2009). Teachers' Beliefs about Student Learning and Motivation.International Handbook of Research on Teachers and Teaching, 21(5), 361-371. New York: Springer. http://dx.doi.org/10.1007/978-0-387-73317-3_23

Wang, M. C., Haertel, G. D., \& Walberg, H. J. (1993). Toward a knowledge base for school learning. Review of Educational Research, 63, 249-294. http://dx.doi.org/10.2307/1170546

Weiss, R. H. (2006). Grundintelligenztest Skala 2 - Revision [Basic intelligencescale 2 -revision). Göttingen: Hogrefe.

Verschaffel, L. (2002). Taking the modelling perspective seriously at the elementary school level: Promises and pitfalls. Paper presented at the PME Norwich.

Verschaffel, L., De Corte, E., Lasure, S., Van Vaerenbergh, G., Bogaerts, H., \& Ratinckx, E. (1999). Learning to solve mathematical application problems: A design experiment with fifth graders. Mathematicalthinking and learning, 1(3), 195-229. http://dx.doi.org/10.1207/s15327833mt10103_2

\section{(c)) EY}

This work is licensed under a Creative Commons Attribution 3.0 License. 